\title{
Formulation of the Problem for Calculating the Stress State of a Pillar for a Longwall Recovery Room
}

\author{
Vyacheslav Gogolin ${ }^{1}$, Inna Ermakova $^{1 *}$, Vyacheslav Fedusov ${ }^{2}$ \\ ${ }^{1}$ Kuzbass State Technical University, 28 Vesennyaya, Kemerovo, 650000, Russia \\ ${ }^{2}$ JSC SUEK-Kuzbass, 1 Vasilieva, Leninsk-Kuznetsky, 652507, Russia
}

\begin{abstract}
Two statements of the problem of calculating the stress state of pillars for a longwall recovery room are proposed. In the first statement, this pillar is located in the coal seam and is not affected by the adjacent extracted panel. The second statement takes into account the geomechanical effect of the adjacent extracted panel. The calculation area consists of the following blocks: the coal seam, the goaf, and the interpanel pillar. All blocks are affected by their own weight. The problems are solved using the finite element method with pre-determined limiting conditions of the stress state within the solid strata.
\end{abstract}

\section{Introduction}

The final stage in longwall mining along strike is longwall recovery. For this purpose, in modern mines a recovery room is formed within a $14 \div 17 \mathrm{~m}$ wide pillar, depending on the thickness of the seam. Paper [1] discusses the research results and shows that the position of the recovery room relative to the adjacent previously extracted panel has a significant effect on the duration of recovery works.

In Figure 1, the red line marks the location of type 1, 2, and 3 recovery rooms in the mines of JSC SUEK-Kuzbass.

\footnotetext{
*Corresponding author: eia.pm@,kuzstu.ru
} 
a)

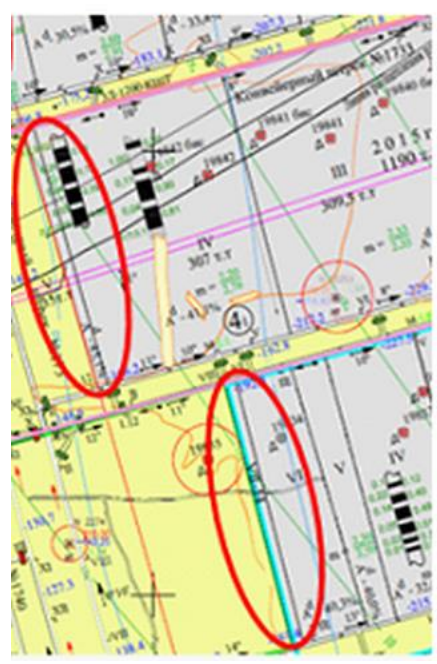

b)

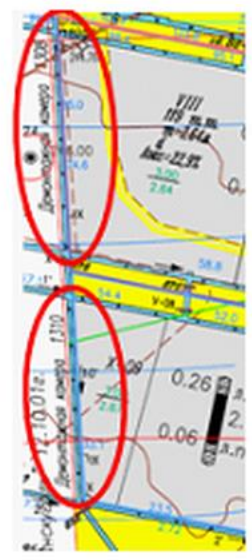

c)

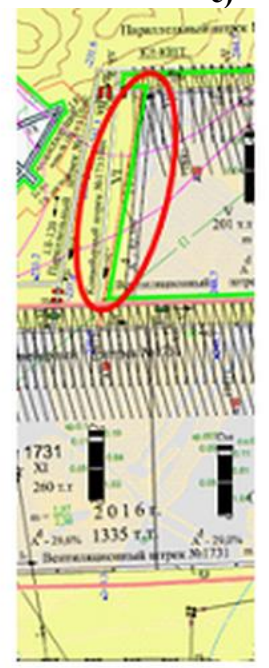

Fig. 1. The location of type 1 (a), 2 (b) and 3 (c) recovery rooms.

Figure 1a shows type 1 recovery rooms. The seam was mined to the rise. In this case, each recovery room and the associated pillar were located outside the zone affected by the goaf of the previously extracted panel.

Figure $1 \mathrm{~b}$ shows type 2 recovery rooms. In this case, the recovery rooms of contiguous panels are located at the same level.

Figure 1c shows a type 3 recovery room which is located next to the goaf of the previously extracted panel.

It is important to find out about the stress and strength state of the pillar for the recovery room because once the recovery room is formed, the stress will affect the powered roof supports. This will determine the duration of support recovery.

Let us consider two main types of location of a pillar for a recovery room.

Figure 2 shows the location of the pillar for a type 1 recovery room in plan, as well as two vertical sections: across the pillar $(\mathrm{A}-\mathrm{A})$ and along the pillar $(\mathrm{B}-\mathrm{B})$. 

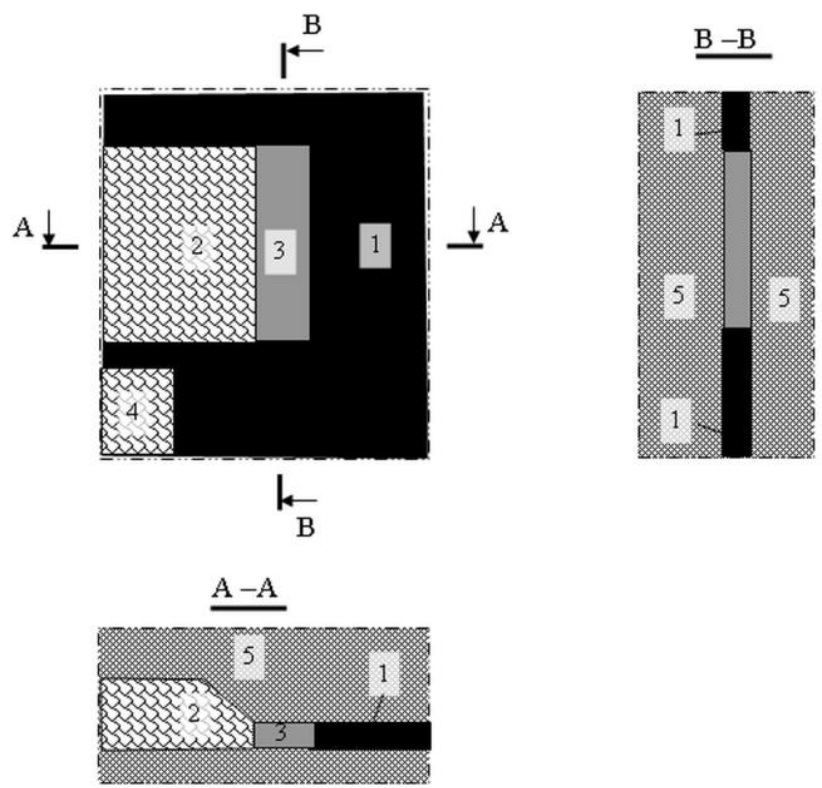

Fig. 2. The location of a pillar for a type 1 recovery room: 1 - coal pillar; 2 - goaf of the working longwall; 3 - pillar for the recovery room; 4 - goaf of the previously extracted panel; 5 - main floor and roof rocks.

Figure 3 shows the location of a pillar for a type 3 recovery room and two vertical sections: across the pillar $(\mathrm{A}-\mathrm{A})$ and along the pillar $(\mathrm{B}-\mathrm{B})$.

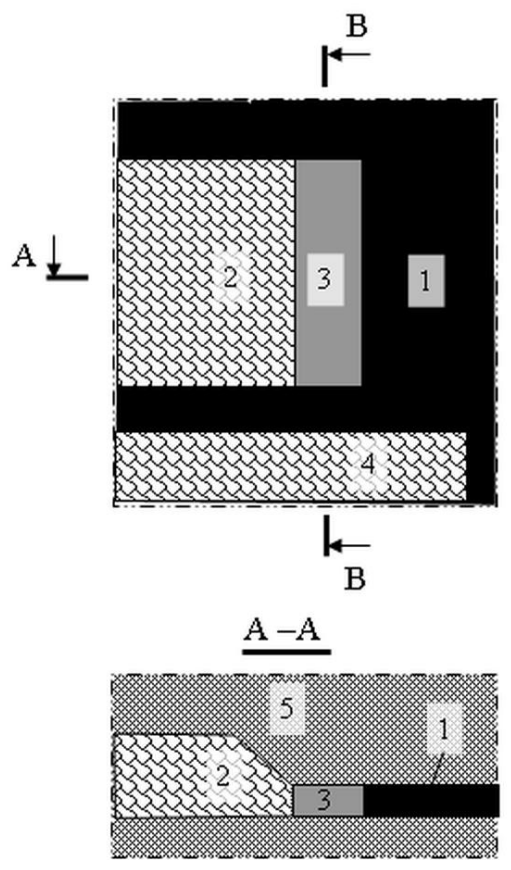

Fig. 3. The location of a pillar for a type 3 recovery room: 1 - coal pillar; 2 - goaf of the working longwall; 3 - pillar for the recovery room; 4 - goaf of the previously extracted panel; 5 - main floor and roof rocks. 
Along section A-A, in both cases, the stress from the previously extracted panel (2) acts on the pillar (3) for the recovery room.

If a type 3 recovery room is located along the $\mathrm{B}-\mathrm{B}$ section, additional stress acts on the pillar for the recovery room (3) from the previously extracted panel (4), which is transmitted through the inter-panel pillar (1).

Thus, the pillar for the recovery room can carry the stress-induced load in one or two main directions: across (the A-A section) and along (the $\mathrm{B}-\mathrm{B}$ section) the pillar under consideration.

The design diagrams of the stress state of the pillar are shown in Figure 4.

Roof rocks are represented by the main components - the immediate and the main roof. Thus, the problem has the following key parameters: the mining depth, the seam thickness, the immediate roof thickness, and the deformation and strength properties of the seam and the roof.

The solution area consists of the following blocks: 1 - coal seam; 2 - goaf of the previously extracted panel; 3 - pillar for the recovery room; 4 - the immediate roof rocks; 5 - the main floor and roof rocks; 6 - the inter-panel pillar.

a)

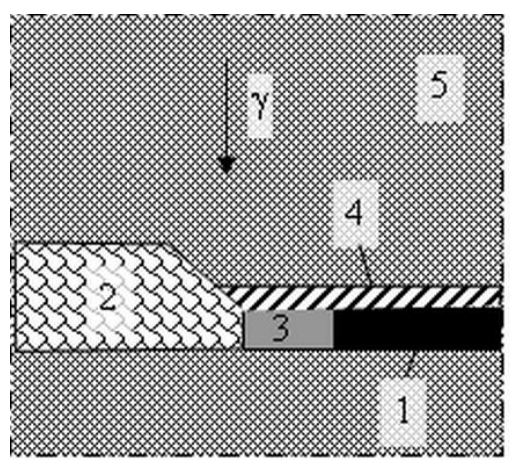

b)

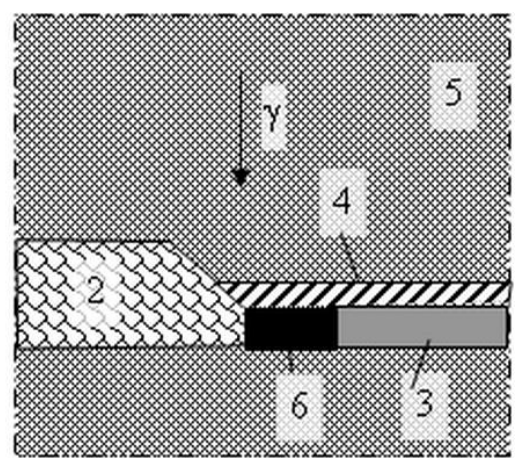

Fig. 4. Design diagrams of the stress state of the pillar for the recovery room: a) across the pillar; b) along the pillar: 1 - coal seam; 2 - goaf; 3 - pillar for the recovery room; 4 - the immediate roof rocks; 5 - the main floor and roof rocks; 6 - the inter-panel pillar.

The main floor and roof rocks, the seam, the pillar for the recovery room and the goaf are loaded with a volumetric force corresponding to the weight of the blocks. The height of the caving zone is $5 \mathrm{x}$ the seam thickness. At the edges of the design area, which is sufficiently distant from the pillar, normal displacements and shear stresses are taken to be equal to zero. The pillar is subjected to loads, which results in its partial failure. To take into account the partial loss of strength of the pillar, the technique described in [2] is used. The idea behind this technique is that a nonlinear problem that takes into account the outof-limit deformation of a coal seam is replaced by an equivalent linear problem which introduces a non-homogeneous area in the edge section of the seam.

\section{Methods}

Since the solution area consists of several blocks with various deformation and strength properties, the finite element method (FEM) is used in this paper. The finite element method is widely used in solving geomechanical problems in mining [3-12].

There are various standard FEM software packages. We used a Russian package "ELCUT" licensed product. The software enables the following parameters to be calculated: stresses, principal stresses, deformations, displacements, and strength based on 
various criteria. To visualize the solution, one can view the images of the stress-strain state of the area to be solved, displacement vectors, and principal stress tensors. There are special procedures for summing up the load on a certain section within the area to be solved, as well as for deriving the values of the investigated parameters at any point.

\section{Findings}

Test calculations of the stress and strength state have been conducted for the mining environment in Nadbaikimsky seam of Rubana mine, JSC SUEK-Kuzbass. The structure of the roof rocks is shown in the table below. The longwall face width was taken as $300 \mathrm{~m}$, the width of the inter-panel pillar is $30 \mathrm{~m}$, and the width of the pillar for the recovery room is $14 \mathrm{~m}$ (see Figure 4b).

Table. Structural column for the Nadbaikimsky seam, LW 1210.

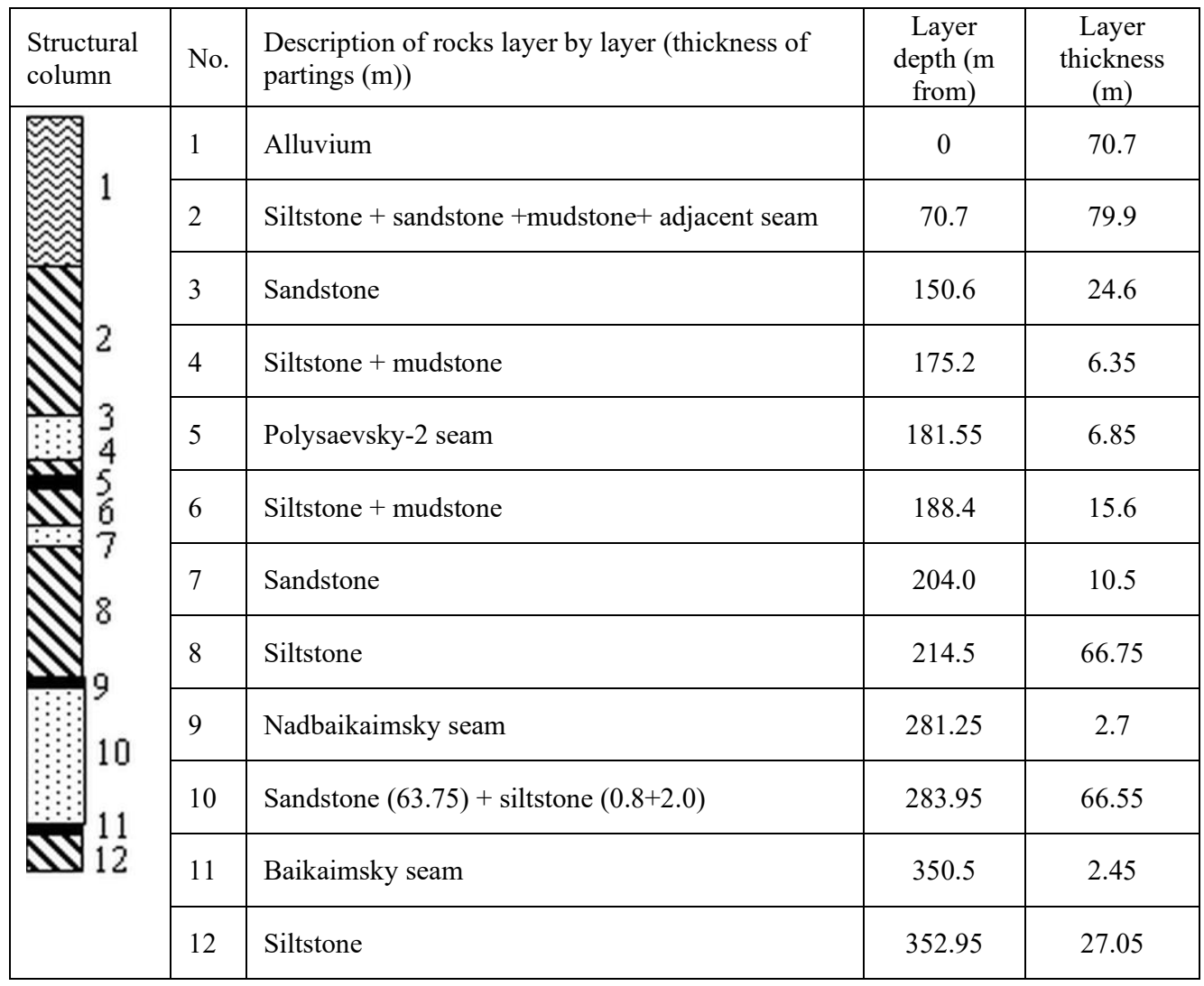

The deformation and strength properties of the adjacent strata were averaged based on their values for each layer and its thickness.

Figure 5 shows the distribution of vertical stresses in the strata. Here, the vertical compressive stresses are negative. 

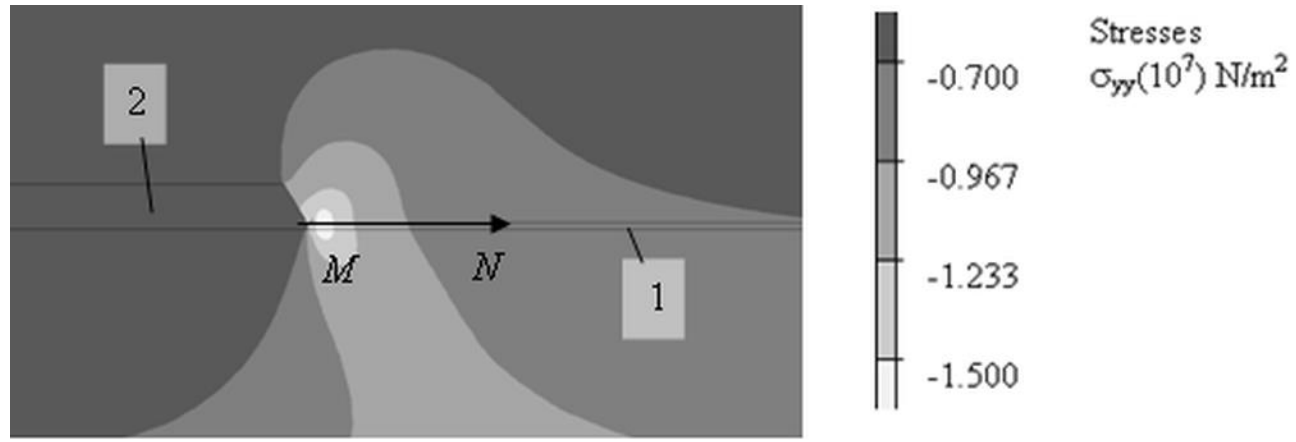

Fig. 5. Distribution of vertical stresses in the strata: 1 - coal seam; 2 - goaf.

In Figure 5, the darkest color shows the destressing area within the strata. The area of the highest stress is highlighted in white. The values of vertical stresses in the roof of the seam in the MN opposite direction of the goaf are shown in Figure 4.

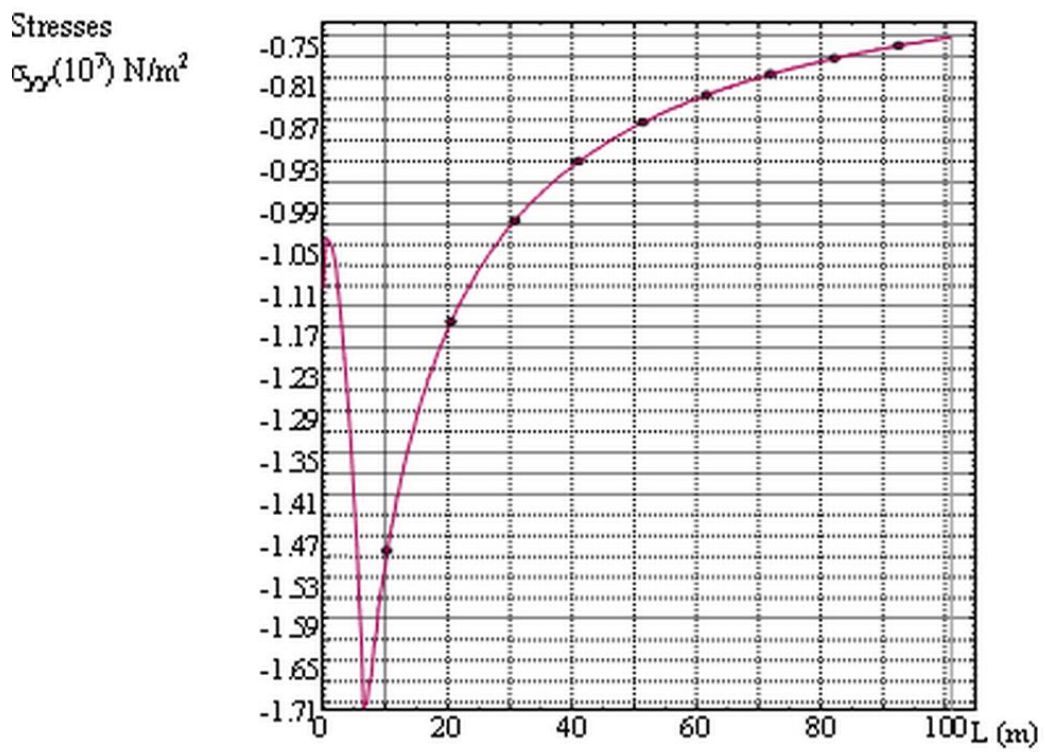

Fig. 6. Values of vertical stresses in the roof of the seam in the opposite direction of the goaf.

The calculation results in the considered example are consistent with the results of observations during the longwall recoveries. Further research will focus on establishing the trends in the change of the stress and strength state of the pillar for the recovery room based on geological and mining factors.

\section{Conclusion}

1. A pillar for a recovery room can be located next to the goaf of the previously extracted panel. This layout significantly increases the duration of recovery works.

2. When calculating the stress-strain state of the pillar for the recovery room, it is necessary to keep in mind that it can carry the stress-induced load in one or two main directions: across the pillar from the working longwall and along the pillar from the previously extracted panel. 
3. The finite element method enables the total loads on the pillar for the recovery room to be calculated, depending on various factors.

\section{References}

1. I.A. Ermakova, V.A. Fedusov, E3S Web of Conferences. 5. "5th International Innovative Mining Symposium, IIMS 2020" (2020)

2. I.A. Ermakova, N.N. Pirieva, Coal in the 21st Century: Mining, Processing and Safety (2016)

3. A.M. Lin'kov, On the Theory of Pillar Design. Journal of Mining Science, 37(1) (2001)

4. O.C. Zienkiewicz, R.L. Taylor, and J.Z. Zhu, The Finite Element Method: Its Basis and Fundamentals (7th Edition). Butterworth-Heinemann (2013)

5. V. Zubov, G. Karpov, International Multidisciplinary Scientific GeoConference Surveying Geology and Mining Ecology Management, SGEM 14th, 299, 12 (2014)

6. O. Kazanin, V. Klimov, V. Alekseev, A. Sidorenko, IJCIET, 10:02, 87 (2019)

7. J.A.L. Napier, D.F.Malan, International Journal of Rock Mechanics and Mining Sciences, 109, 76 (2018)

8. I.E. Shipovskii, V.A. Trofimov, O.N. Malinnikova, W.-J. Xu, AIP Conference Proceedings. Proceedings of the International Conference on Advanced Materials with Hierarchical Structure for New Technologies and Reliable Structures (2019)

9. Slashchov I., E3S Web of Conferences (2019)

10. A.B. Tsvetkov, L.D. Pavlova, IOP Conference Series: Earth and Environmental Science, Novokuznetsk, (2018) 